\title{
Marker-assisted Selection of New Compounds in Moringa oleifera Lam. Induced by Gamma Irradiation
}

\author{
Hanan M. Mansour ${ }^{(1)}$, Nahla Hamideldin(1)\#, F.M. Abdel-Tawab ${ }^{(2)}$ and Eman M. \\ Fahmy ${ }^{(2)}$ \\ (1)Natural Products Research Deprtment, National Center for Radiation Research \\ \& Technology, Atomic Energy Authority (AEA), P.O.Box 29 Nasr City, Cairo and \\ ${ }^{(2)}$ Genetics Deprtment, Faculty of Agriculture, Ain Shams University, Shoubra El \\ Kheima, Cairo, Egypt.
}

\begin{abstract}
$\mathbf{T}$ HE DRY seeds of the medicinal plant Moringa oleifera were exposed to four gamma rays doses (0, 20, 40 and 60Gy) using ${ }^{60} \mathrm{Co}$ gamma unit (Indian gamma cell), that delivered $2.25 \mathrm{kGy}$ per hour. Gas chromatography-mass spectrometry (GC-MS) analysis was performed to identify the chemical profile of the ethanol extracts of non-irradiated and gamma irradiated (20, 40 and 60Gy) leaf samples of Moringa oleifera. New chemical compounds such as 5-hydroxymethylfurfural (5-HMF) and 2, 3-dihydro-3, 5-dihydroxy-6-methyl-4H-pyran-4-one (DDMP) were detected in the irradiated samples. Ten start codon-targeted (SCoT) primers were used to detect markers correlated with the appearance of 5-HMF and DDMP. Twenty four markers have been used for assessing the new compounds at the three radiation doses used. Nine of them represented positive markers that appeared in the plants treated with each of the three doses under study (20, 40 and 60Gy), but they were absent in the corresponding control. On the other hand, fifteen bands represented negative markers that appeared in non-irradiated samples and were absent in the irradiated ones. The primer SCoT 5 showed the highest percentage of polymorphism (83.3\%).
\end{abstract}

Keywords : Moringa oleifera, Gamma rays, GC-MS, SCOT-marker.

\section{Introduction}

Since earliest times, herbs have been prized for their pain-relieving and healing abilities and even at present, people still rely largely on medicinal plants for their curative properties. According to the World Health Organization, $80 \%$ of people living in rural areas depend on medicinal herbs as primary health care systems (Sundaram et al., 2011).

Moringa species are well documented as herbs for their extraordinary nutritional and medicinal properties. Moringa oleifera Lam. is the most widely cultivated species of the monogenic family, Moringaceae (Fahey, 2005). These species are known as anti-helminthics antibiotics, detoxifiers, immune builders and have been used to treat malaria (Thilza et al., 2010). There are about 13 species of Moringa trees in the family Moringaceae. They are native to India, the Red Sea area, and/or parts of Africa, including Madagascar. Ancient Egyptians used Moringa oleifera oil for its cosmetic value and skin preparations (Mahmood et al., 2010). Although Moringa oleifera was not popular among the Greeks and Romans, they were aware of its medical properties (Fahey, 2005). Moringa oleifera is an interesting plant for its contribution to bioactive compounds. In particular, the leaves are the most used part of the plant (Leone et al., 2015). Many investigators have reported that the leaves are rich in phytochemical compounds; vitamins, carotenoids, polyphenols, phenolic acids, flavonoids, alkaloids, glucosinolates, isothiocyanates, tannins and saponins, in addition to several antioxidant enzymes. However, the leaves showed a high variation in the amounts of bioactive compounds because of the plants genetic characteristics (Mukunzi et al., 2011).

Gamma radiation (high frequency electromagnetic radiation) is an important ionizing ray, as it comprises of high-energy

\#Corresponding author email: n.hamideldin@yahoo.com 
photons. The high penetration property of photons causes ionization of matter in plants by indirect interaction (Vandenhove et al., 2010).

Esnault et al. (2010) showed that gamma rays modified plant growth and development, caused DNA damage, and interrupted metabolic pathways. Gamma radiation induced changes in the gas chromatography- mass spectrometry (GCMS) profile of essential oils in plants (Shim et al., 2009 and Silva et al., 2013).

Collard \& Mackill (2009) developed a novel method for generating plant DNA markers based on the short conserved region flanking the ATG start codon in plant genes. Using single 18-mer primers in a single primer polymerase chain reaction (PCR), the authors reported that start codon targeted (SCoT) markers were generally reproducible, but it was suggested to be used in conjunction with markers for applications such as genetic analysis, bulked segregant analysis, and quantitative trait loci mapping, especially in laboratories with a preference for agarose gel electrophoresis.

Gorji et al. (2011) compared three molecular marker techniques: Start codon targeted (SCT), inter-simple sequence repeats (ISSRs) and random amplified polymorphic DNA (RAPD) markers for fingerprinting of 24 varieties and a segregating population of tetraploid potato. SCoT markers were more informative, followed by ISSRs marker, as compared to other markers, for assessing varieties based on polymorphism information content. DNA markers are produced by PCR using a single primer that is designed from the short conserved region flanking the ATG start codon. Interestingly, out of 2857 scientific publications on $M$. oleifera in the primary database (Web of Science), only 12 included genetic characterization based on molecular markers. Furthermore, data of only 77 fragments of DNA and RNA sequences are available in the National Center for Biotechnology Information (NCBI) nucleotide database (Leone et al., 2015).

The objectiveof the present study is to identify the possible effects of different doses of gamma irradiation on the phytochemical constituents in the ethanol extracts of Moringa oleifera leaves, using GC-MS. It has been also intended to detect molecular markers associated with active ingredients.

\section{Materials and Methods}

A field experiment was conducted in a sunny greenhouse at the Natural Products Research Department, National Center for Radiation Research and Technology (NCRRT), Atomic Energy Authority (AEA), Cairo, Egypt. The laboratory experiments were distributed between NCRRT, the Department of Genetics, Faculty of Agriculture, Ain Shams University, Cairo, Egypt and the Central Laboratory of Pesticides, Ministry of Agriculture, Giza, Egypt.

\section{Plant materials}

The seeds of $M$. oleifera were obtained from the Desert Research Center, Cairo, Egypt. The dry seeds were exposed to four gamma rays doses (0, 20, 40 and 60Gy). Gamma irradiation was performed at the NCRRT, Cairo, Egypt. Irradiation treatments were conducted using a ${ }^{60} \mathrm{Co}$ gamma unit (Indian gamma cell), which delivered $2.25 \mathrm{kGy}$ per hour.

\section{Methods}

Some seeds were not irradiated and used as control. The irradiated and non-irradiated seeds were soaked in warm water for $30 \mathrm{~min}$ to activate germination and then were sown in plastic bags $(10 \times 20 \mathrm{~cm})$ each filled with $1 \mathrm{~kg}$ of soil. The soil was a mixture of compost and sand at a rate of $1: 3$ to $2: 3$, respectively, with three replicates for each treatment containing 25 plastic bags with one seed per bag. After 2 months, the plantlets were transferred to the field. The experiment was carried out in a completely randomized experimental design.

\section{$G C-M S$ analysis}

Sample preparation: Five individual plants were taken from every replicate for each treatment and the control to determine the effect of gamma rays on the phytochemical profile of $M$. oleifera leaves.

Fresh leaves $(10 \mathrm{~g})$ were macerated in $20-30 \mathrm{ml}$ $80 \%$ ethanol for at least 10 days at $37^{\circ} \mathrm{C}$. The alcohol was clarified and the remained tissue was re-extracted with $20-30 \mathrm{ml} 80 \%$ ethanol for three times. Finally, clarified extracts were collected together and evaporated

Sample analysis: The samples were analyzed on a Hewlett-Packard model 6890 Series GC system equipped with a HP 5973 MS detector 
(EI mode, 70eV). A capillary column type, HP-5 (5\% phenyl dimethyl-siloxane), 30m length, inner diameter $0.25 \mathrm{~mm}$ and a film thickness of $0.25 \mu \mathrm{m}$ was used. The column temperature was programmed to be increased after $5 \mathrm{~min}$ from 70 to $150^{\circ} \mathrm{C}$ at the rate of $2^{\circ} \mathrm{C} / \mathrm{min}$ and then after $5 \mathrm{~min}$ from 150 to $250^{\circ} \mathrm{C}$ at the rate of $1^{\circ} \mathrm{C} / \mathrm{min}$. Helium was used as a carrier gas at a flow rate of $1 \mathrm{ml} /$ min. The injector and detector temperatures were $250^{\circ} \mathrm{C}$ and $280^{\circ} \mathrm{C}$, respectively. The components in the sample extract were identified by comparing gas chromatographic retention indices (Adams 1), and mass spectra from Wiley MS Chemstation Libraries (6 ${ }^{\text {th }}$ ed., G 1034, Rev.C.00.00, HewlettPackard, Palo Alto, CA, USA).

\section{SCoT-marker analysis}

Genomic DNA extraction: DNA extraction from leaves of the first season plants was performed according to the method outlined by Graham \& Henry (1997).

SCoT-marker method: Start codon targeted (SCoT) polymorphism is a simple DNA marker technique for generating gene-targeted markers in plants. Ten primers with 18-mer, ATG sequence and with $\mathrm{GC} \%$ content between $50 \%$ and $72 \%$ were used Table 1.

TABLE 1. The sequences of the ten used SCoT primers.

\begin{tabular}{lcc}
\hline $\begin{array}{l}\text { SCoT } \\
\text { primer }\end{array}$ & Sequence (5'-3') & \%GC \\
\hline S5 & CAACAATGGCTACCACGA & 50 \\
S7 & CAACAATGGCTACCACGG & 56 \\
S10 & CAACAATGGCTACCAGCC & 56 \\
S18 & ACCATGGCTACCACCGCC & 67 \\
S22 & AACCATGGCTACCACCAC & 56 \\
S26 & ACCATGGCTACCACCGTC & 61 \\
S31 & CCATGGCTACCACCGCCT & 67 \\
S32 & CCATGGCTACCACCGCAC & 67 \\
S34 & ACCATGGCTACCACCGCA & 61 \\
S35 & CATGGCTACCACCGGCCC & 72 \\
\hline
\end{tabular}

SCoT protocol: The amplification reactions were used in a final volume of $25 \mu \mathrm{l}$ containing the following:

Buffer 10X (2.5 $\mu \mathrm{l}), \mathrm{MgCl}_{2} 25 \mathrm{mM}(2.5 \mu \mathrm{l})$, dNTPs $40 \mathrm{mM}(0.5 \mu \mathrm{l})$, Taq DNA polymerase 1 unit $/ 1 \mu \mathrm{L}$ $(1.0 \mu \mathrm{l})$, Template DNA 50ng/ $\mu \mathrm{l}(2.0 \mu \mathrm{l})$, Primer $0.4 \mu \mathrm{M}(2.0 \mu \mathrm{l}), \mathrm{H}_{2} \mathrm{O}$ dd (up to $25.0 \mu \mathrm{l}$ ). Reactions were performed in a DNA thermal cycler- PCR (Progene 30, Techno, Cambridge Ltd., Duxford,
Cambridge, UK). The thermal cycler was programmed for three main steps as follows: At $94^{\circ} \mathrm{C}$ for $3 \mathrm{~min}, 35$ cycles, $\left\{94^{\circ} \mathrm{C}\right.$ for $30 \mathrm{sec}, 50^{\circ} \mathrm{C}$ for $1 \mathrm{~min}, 72^{\circ} \mathrm{C}$ for $\left.90 \mathrm{sec}\right\}$ then one cycle at $72^{\circ} \mathrm{C}$ for $7 \mathrm{~min}$ and at $4^{\circ} \mathrm{C}$ (infinite).

\section{Results}

The results of ethanol extract of $M$. oleifera leaves showed a wide range of differences among radiation treatments, or within the same treatment, as compared with the control. In general, 84 chemical compounds were recognized as shown in Table 2. The compounds were classified into different groups and arranged according to their retention time (RT).

In the control sample, 29 chemical compounds were found as shown in Table 2. The compounds included alcohols, carbonyl compounds, lipids, steroids compounds, phenols, fatty acids and benzenoids. Most of the recognized compounds were classified as fatty acids (Table 2d). The compound 9, 12, 15-octadecatrienoic acid, ethyl ester (linoleic acid, ethyl ester) scored the highest ratio in Moringa leaf ethanol extract (29.77\%). Many important compounds were recognized in the extract with a peak percentage mentioned in parentheses. These compounds represented phytol (7.14\%), acetic acid (2.85\%), alphatocopherol "Vitamin E" (2.16\%) (Table 2a), betasitosterol (2.84\%) fucosterol (2.24\%) (Table 2b). Table $2 \mathrm{~d}$ shows the occurrence of hexadecanoic acid "palmitic acid" (5.62\%), decanoic acid "n-capric acid" (1.52\%) and octanoic acid "caprylic acid" (2.15\%) Benzenoids compounds; 1 2-benzenedicarboxylic acid, bis (2-ethylhexyl) ester $(0.98 \%), 1,2$-benzenedicarboxylic acid, diethyl ester "Diethyl phthalate (DEP)" (2.49\%) and 1, 2-benzenedicarboxylic acid, and bis (2-methylpropyl) ester "Diisobutyl phthalate (DiBP)" (2.24\%) are also shown in Table 2e.

Gamma irradiation showed a difference between the irradiated and non-irradiated leaf sample extracts. As shown in Table 2c, polyphenols showed an increase in the level of the examined samples under the three used doses (20, 40, 60Gy), compared with the control. New polyphenol compounds such as 1, 2 benzenediol, benzaldehyde, 4-hydroxy (vanillin), phenol, 2-ethyl and phosphoric acid were found in some irradiated samples, but not in those of corresponding control. 


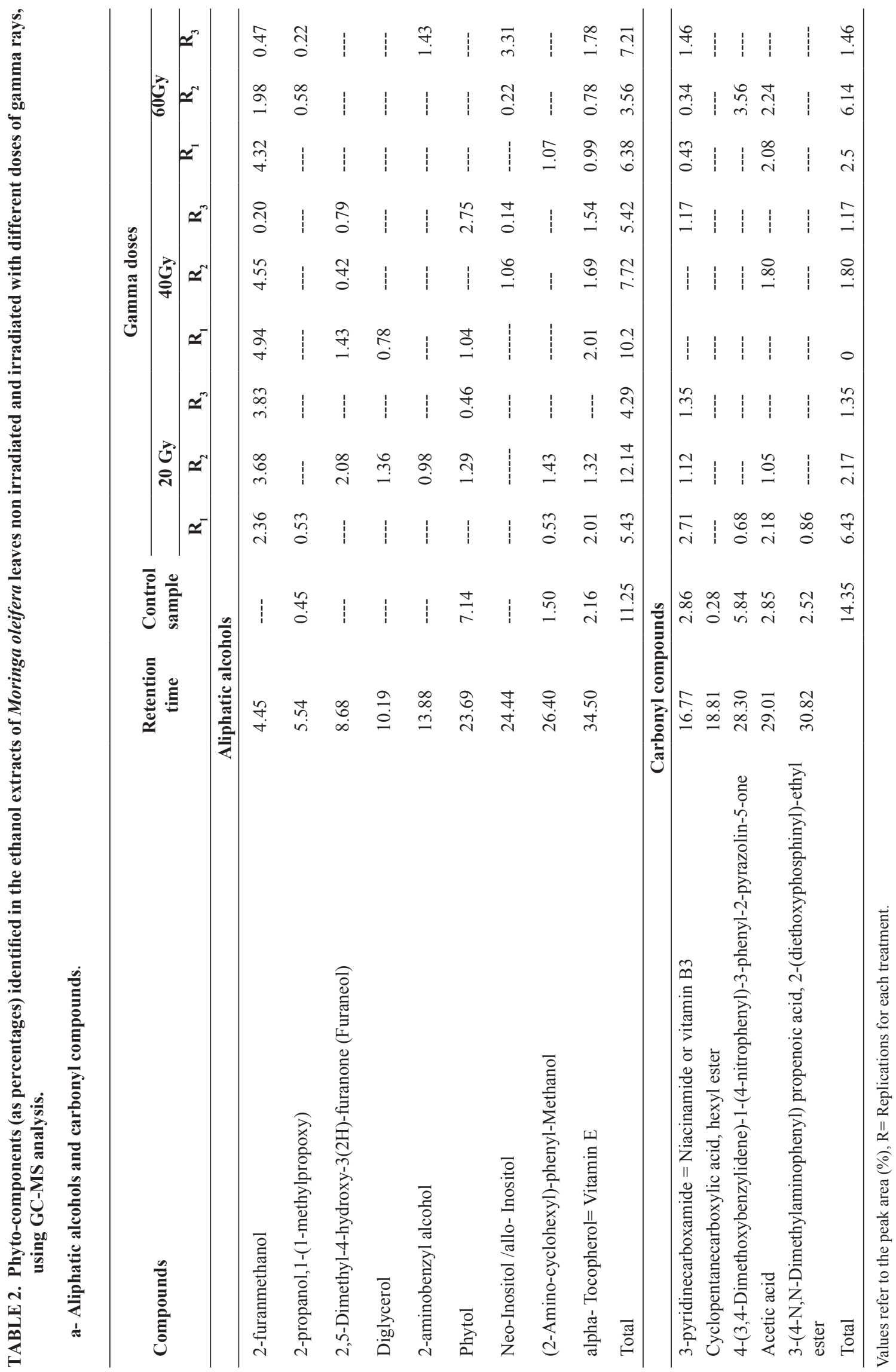

Egypt. J."Rad. Sci. Applic. 31, No.1 (2018) 


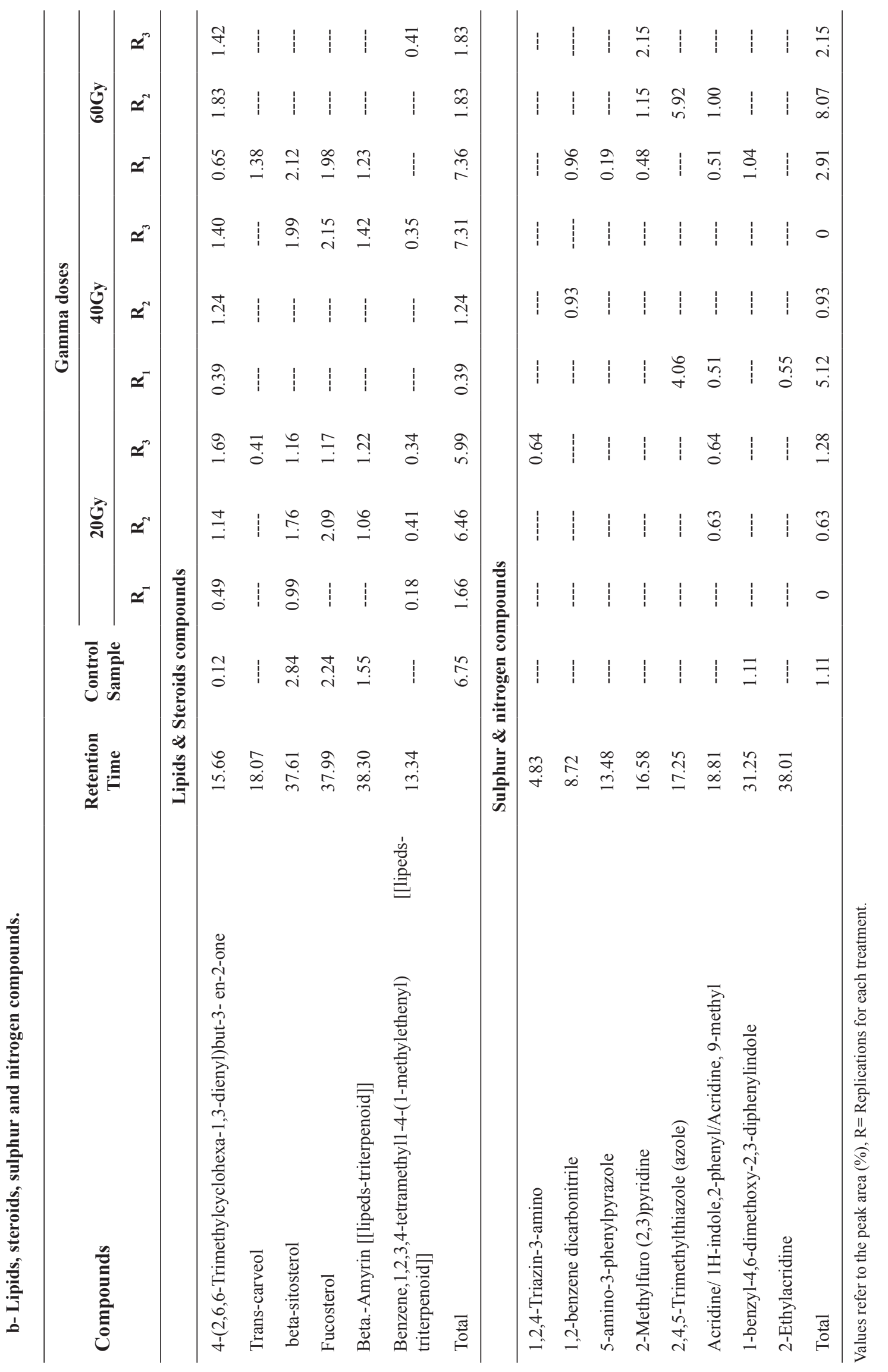

Egypt. J."Rad. Sci. Applic. 31, No.1 (2018) 


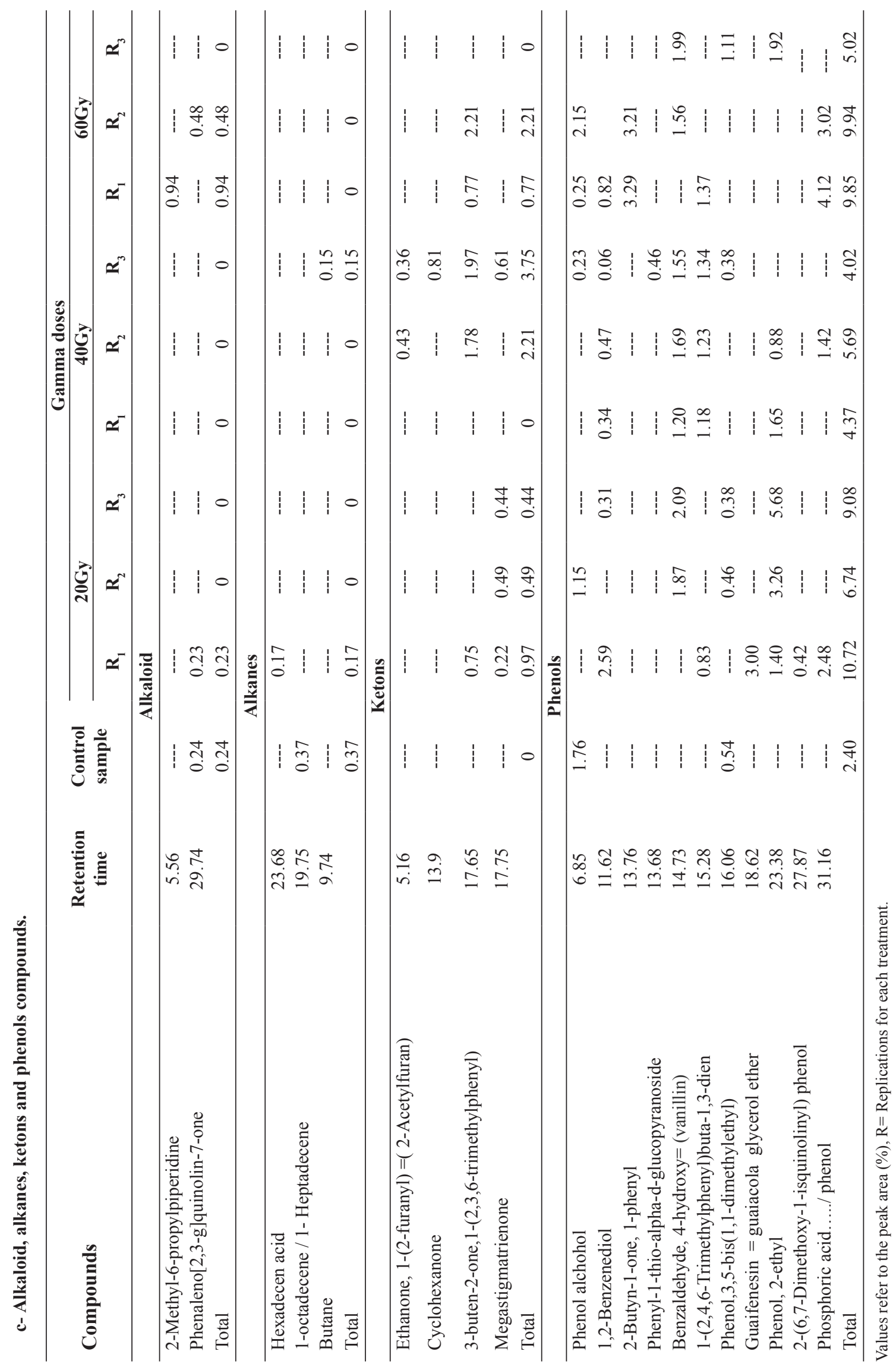

Egypt. J."Rad. Sci. Applic. 31, No.1 (2018) 


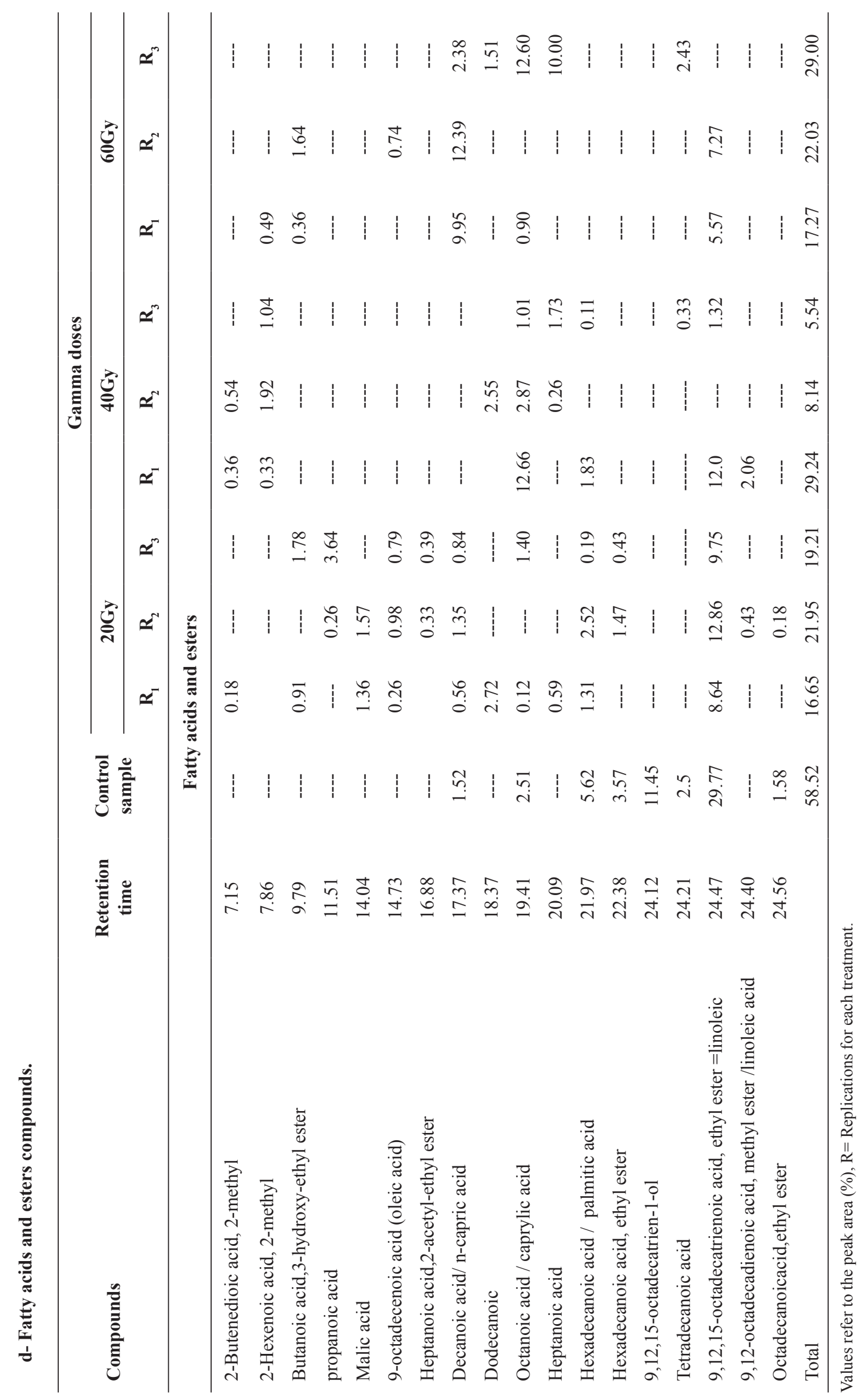

Egypt. J."Rad. Sci. Applic. 31, No.1 (2018) 


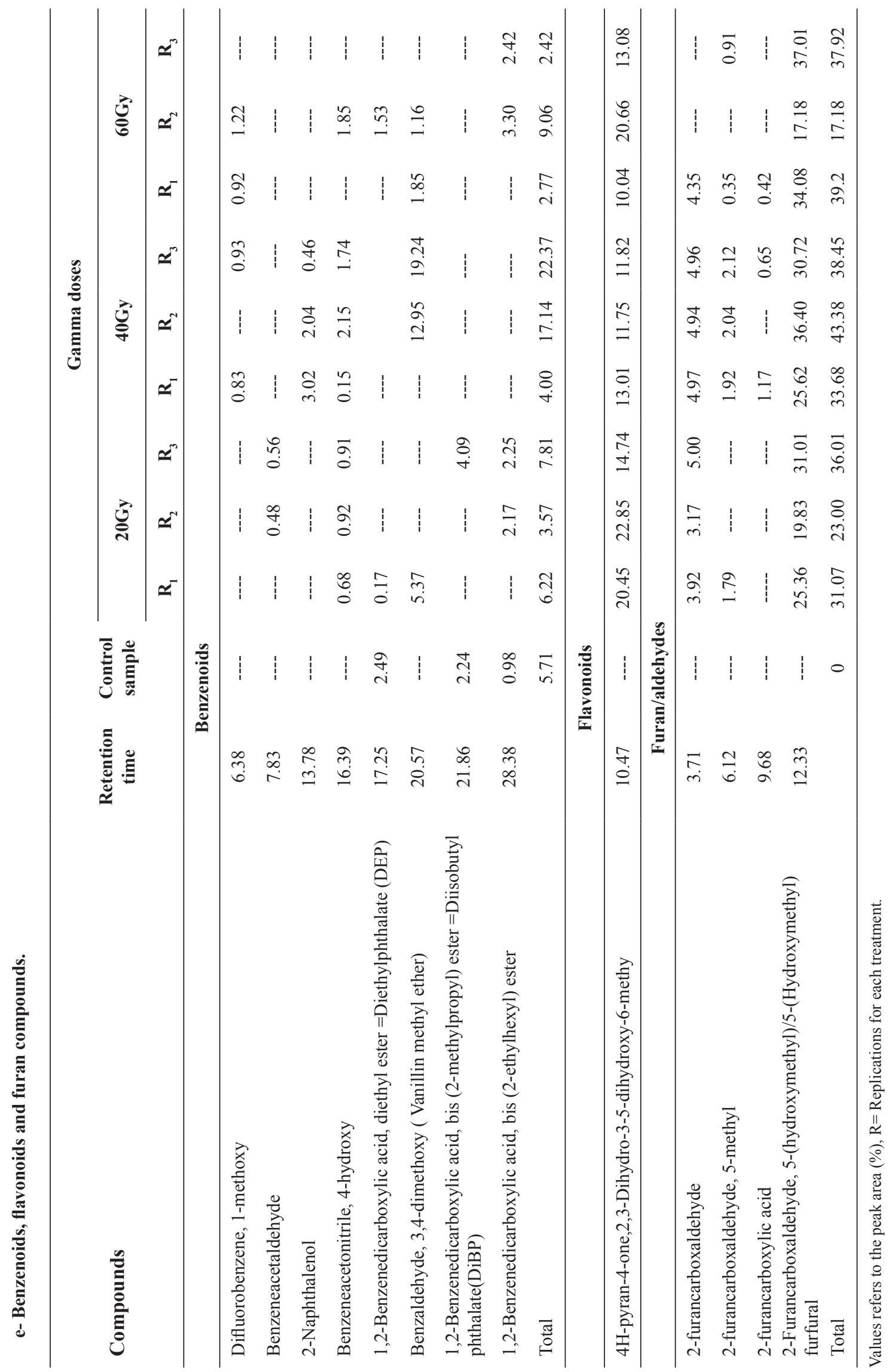

Egypt. J."Rad. Sci. Applic. 31, No.1 (2018) 
As shown in Table $2 b$, radiation did not show similar effects, regarding the levels of total lipids, steroid compounds, as well as sulphur and nitrogen compounds. Some samples showed increases in total ratios, while others exhibited decreases in these ratios, compared with their control. Radiation caused the appearance of some new compounds that were not detected in nonirradiated leaf extracts. However, the induced new compounds showed variable levels according to the applied dose of irradiation; e.g. trans-carveol, 2,4,5-trimethyl thiazole (azole), acridine, 1,2,4 triazin-3-amino, 1,2 benzene dicarbonitrile, 5 amino-3-phenylpyrazole and 2 -methylfuro $(2,3)$ pyridine.

At the level of total benzenoids (Table 2e) radiation did not show a similar effect on the irradiated leaf extracts regarding the antimicrobial chemical compound 1, 2-benzene dicarboxylic acid, bis (2-ethylhexyl) ester.

All irradiated samples showed decreases in the total ratio of fatty acids compounds, compared with the control. The results showed asymmetrical distribution of various fatty acids between the samples. Compared with the control, many saturated and non-saturated fatty acids were found in some irradiated samples for example, 2-butenedioic acid; 2-methyl; 2-hexenoic acid; 2-methyl, butanoic acid; 3-hydroxy-ethyl ester; propanoic acid malic acid; 9-octadecenoic acid (oleic acid); heptanoic acid and heptanoic acid 2-acetyl-ethyl ester. Contrariwise, the compound $9,12,15$-octadecatrien-1-ol that was detected in the control sample did not appear in any of the irradiated leaf samples (Table 2d).

In general, several phytochemicals (four compounds) called furan compounds appeared in response to application of the different doses of gamma irradiation, but they were not found in the control samples. A similar result was also observed for 4H-pyran-4-one, 2,3-dihydro-3-5-dihydroxy6-methyl (DDMP) that are classified as flavonoid compounds. It is important to mention that for furans compounds, three of them showed unequal distribution among the irradiated samples, whereas 2-furancarboxaldehyde, 5-(hydroxymethyl) compound was detected in all irradiated samples (Table 2e).

Both 4H-pyran-4-one, 2,3-dihydro-3-5dihydroxy-6-methyl and Furan carboxaldehyde, 5-(hydroxymethyl) compounds were recorded as new ones that appeared in all irradiated samples, but not present in the control. These compounds were found in high ratios, compared with other detected compounds (Table 2e).

\section{Molecular genetic studies \\ SCoT markers}

DNA was isolated from each of the irradiated and non-irradiated leaf samples. The DNA samples obtained from every gamma-treated leaf samples were mixed together for SCoT markers analysis to obtain a marker band that might be related to the appearance or disappearance of DNA fragment in the irradiated samples and linked strongly to the change in phytochemical compounds of the tested samples. The results of the $10 \mathrm{SCoT}$ primers are shown in Fig.1 and Table 3.

The total number of bands was 103 which ranged between 6 to 13 bands using the 10 primers under investigation. Three SCoT primers; S7, S18 and S22 generated the highest number of bands (13), while S34 generated the lowest number (6). Primer S5 corresponded to the highest number of polymorphic bands (10 bands, $83.3 \%$ ), while primer S34 resulted in the lowest number (1 band, 16.0\%). Primers S5, S18 and S26 showed 4 markers, both of primers S22 and S35 exhibited 3 markers, both of primers S7 and S32 showed two markers, primers S31 and S34 produced only one marker, while primer S10 did not represent any marker. This means that 24 markers were present as a total, nine of them were positive markers distinctive to the three doses of 20, 40 and 60GY, while being absent in control sample. Fifteen bands were negative markers that were distinctive to the non-irradiated samples while they were absent in the irradiated samples.

According to the results shown in Table 2e, all irradiated samples were distinctive for appearance of the chemical compounds; 4H-pyran-4one,2,3-dihydro-3-5-dihydroxy-6-methyl and Furancarboxaldehyde, 5-(hydroxymethyl), which were not present in the control sample. Therefore, the appearance and absence of the SCoT bands in the irradiated samples can be used as positive and negative markers that linked to these compounds. According to that, SCoT can be applied to differentiate between different gamma treatments and obtain markers associated with new compound production. 

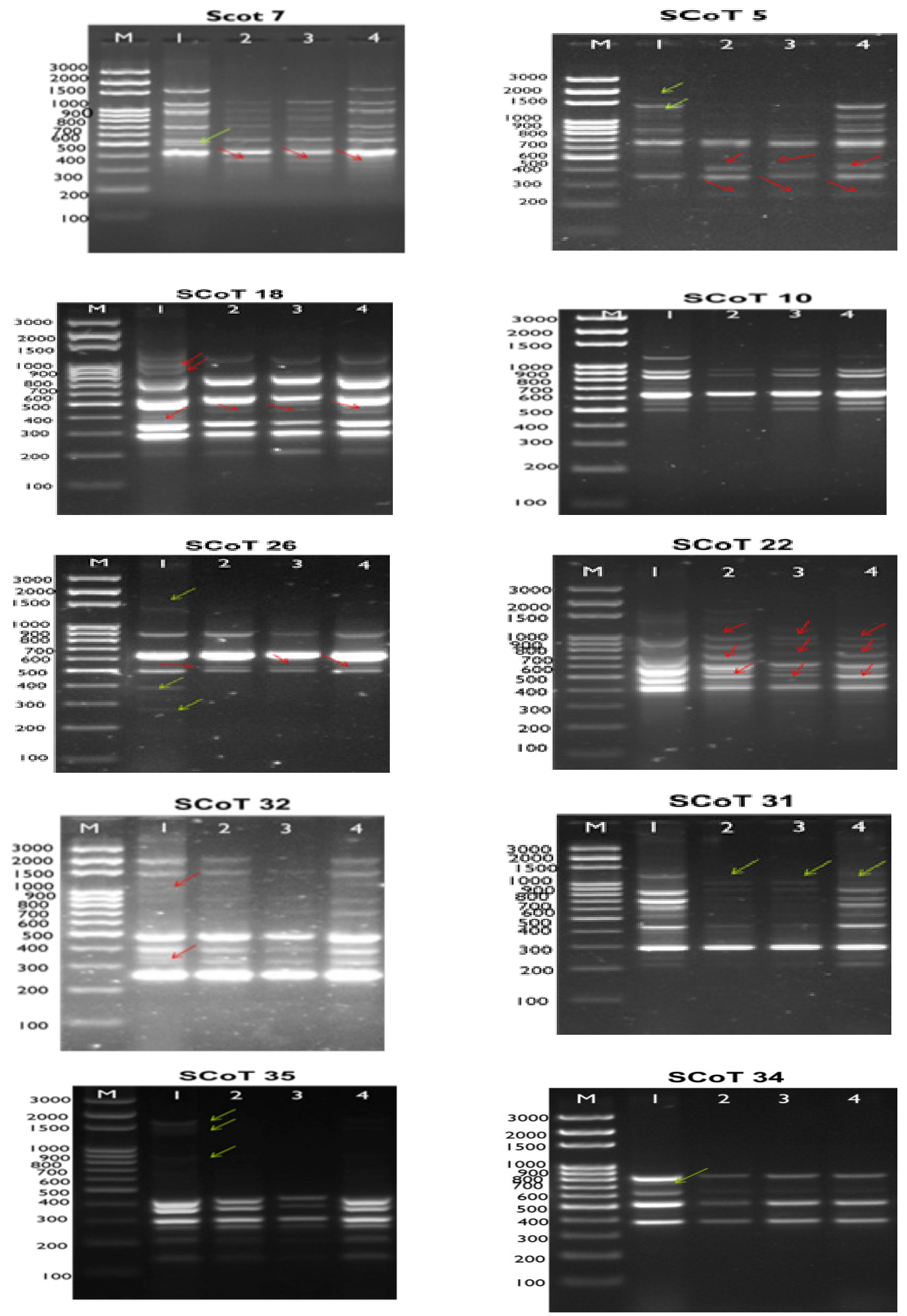

Fig. 1. Bands pattern of ScoT primer with Moringa leaves under four treatments; $M=$ marker, $1=$ control, $2=G y$, $3=40 \mathrm{~Gy}$ and $4=60 \mathrm{~Gy}$; Yellow arrow $=$ Band present, Red arrow $=$ Band absent.

Egypt. J."Rad. Sci. Applic. 31, No.1 (2018) 
TABLE 3. Total number of bands, polymorphic, monomorphic bands and positive and negative markers with each primer.

\begin{tabular}{lccccccc}
\hline Primers & $\begin{array}{c}\text { Total } \\
\text { band } \\
\text { no. }\end{array}$ & $\begin{array}{c}\text { Polymorphic } \\
\text { bands }\end{array}$ & $\begin{array}{c}\text { Polymorphism } \\
\mathbf{( \% )}\end{array}$ & $\begin{array}{c}\text { Monomorphic } \\
\text { bands }\end{array}$ & $\begin{array}{c}\text { Positive } \\
\text { markers }\end{array}$ & $\begin{array}{c}\text { Negative } \\
\text { markers }\end{array}$ & $\begin{array}{c}\text { Total } \\
\text { markers } \\
\text { no. }\end{array}$ \\
\hline S 5 & 12 & 10 & 83.3 & 2 & 2 & 2 & 4 \\
S 7 & 13 & 7 & 53.8 & 6 & 1 & 1 & 2 \\
S 10 & 8 & 3 & 37.5 & 5 & 0 & 0 & 0 \\
S 18 & 13 & 8 & 61.5 & 5 & 1 & 3 & 4 \\
S 22 & 13 & 8 & 61.5 & 5 & 3 & 0 & 3 \\
S 26 & 7 & 4 & 57.1 & 3 & 1 & 3 & 4 \\
S 31 & 11 & 5 & 45.5 & 6 & 1 & 0 & 1 \\
S 32 & 11 & 4 & 36.4 & 7 & 0 & 2 & 2 \\
S 34 & 6 & 1 & 16.0 & 5 & 0 & 1 & 1 \\
S 35 & 9 & 3 & 33.3 & 6 & 0 & 3 & 3 \\
\hline Total & 103 & 53 & 51.5 & 50 & 9 & 15 & 24 \\
\hline
\end{tabular}

\section{Discussion}

The results of ethanol extraction of Moringa oleifera leaves showed a wide range of differences among radiation treatments, or within the same treatment as compared with the control. This was in partial agreement with the results of Bhattacharya et al. (2014) who identified hexadecanoic acid (palmitic acid), alpha-tocopherol and betasitosterol phytochemical compounds in ethanol extract of Moringa leaves of plants cultivated in India. The authors found that hexadecanoic acid was the major compound in the studied leaf extract (28.84\%). Similarly, Karthika et al. (2013) identified both 1, 2-benzenedicarboxylic acid, bis (2-ethylhexyl) ester and diethyl phthalate (DEP) in Moringa leaf extract, and found that the phytochemical compound identified with the maximum peak percentage area was methyl lactate $(21.07 \%)$. Furthermore, the authors found that at the level of total benzenoids, the antimicrobial chemical compound (1, 2-benzene dicarboxylic acid, bis (2-ethylhexyl) ester) showed a twofold increase in four irradiated samples (two at each 20 and 60Gy), compared with the control.

The compounds 4H-pyran-4-one, 2, 3-dihydro-3-5-dihydroxy-6-methyl and Furan carboxaldehyde, 5-(hydroxymethyl) were concomitant with all irradiated samples and have been recorded in many plants. A five-carbonring aromatic aldehyde; 5-hydroxymethylfurfural (5-HMF) was present in coffee, dried fruits and some flavoring agents (Xu et al., 2007). In the last decades, researchers considered the 5-HMF to be hazardous to human health. Several studies have suggested that 5-HMF damages striated mucous membranes and irritates the skin. However, recent studies have shown the pharmacological effects of 5-HMF. These include antioxidant effects (Zhao et al., 2013), anti-ischemic, and anti-tyrosine enzyme effects, and positive hemorheology effects (Li et al., 2011). In addition, hepatoprotective effects were examined by Li et al. (2015) who suggested that 5-HMF hepatoprotective effects on alcoholinduced liver oxidative injury might be due to its potent antioxidant properties.

Mohamed \& Khan (2013) examined the antioxidant activity of chewing stick (miswak), by using the methanol extract of miswak and GC-MS analysis, where the results detected three compounds of furan group; one of them was 2-Furancarboxaldehyde,5-(hydroxymethyl). They suggested that such furan derivatives that contained hydroxyl groups could possess antioxidant activities.

Moreover, according to Gopalakrishnan \& Kalaiarasi (2013), the major phytoconstituents that were found in ethanolic extract of the fruits of Cucumis sativus (using GC-MS analysis) were 2,3-Dihydro-3,5-dihydroxy-6-methyl-4Hpyran-4-one (10.86\%), 2-furancarboxaldehyde, 5-(Hydroxyl methyl) (64.69\%).

The authors suggested that those active constituents might be responsible for many biological activities of cucumber such as antimicrobial, anti-inflammatory and antimicrobial preservative.

Similar effects of gamma radiation was shown on the phytochemical compounds in other medicinal plants. Thus, Seo et al. (2007) found an increase in the amount of essential 
oils in the irradiated samples in Angelica gigas plant, compared with the non-irradiated samples. Similarly, Fanaro et al. (2012) found that gamma irradiation had a substantial influence on the profile of odor chemical compounds in oolong tea and that the dose of $10 \mathrm{kGy}$ caused informed more new compounds.

SCoT markers have recently become the marker of choice in case of genetic diversity studies. The diversity information generated by RAPD, SSRs or ISSRs is based on the non-coding regions of DNA, so the gained information is not directly useful. However, it is useful only when it is linked strongly to some traits, whereas, SCoT markers reveal the genetic diversity at the level of genes. Thus, these markers can help in finding new alleles in a given germplasm collection.

The appearance and absence of the SCoT bands in the irradiated samples can be, respectively used as positive and negative markers linked to these compounds. According to that, SCoT can be applied to differentiate between different gamma treatments and for obtaining markers associated with new compound production.

The simplicity and reproducibility of using SCoT markers led to their being successfully applied for the assessment of genetic diversity and taxonomic study of citrus plants (Han et al., 2011), Dimocarpus longan (Chen et al., 2010) and date palm cultivars (AL-Qurainy et al., 2015) and 53 Elymus sibiricus from distribution area in China (Zhang et al., 2015). However, Sankhla et al. (2015) reported that SCoT markers have emerged as a superior system, compared to RAPD, and Shahlaei et al. (2014) found that SCoT markers were more informative than the ISSR molecular system in the genetic diversity analysis of ten tomato varieties. In contrast, polymorphism detected by SCoT markers in the genetic diversity study of date palm cultivars (AL-Qurainy et al., 2015) was low as compared with other markers such as RAPD (Bahraminejad \& Nejad, 2015) and SSR (Racchi et al., 2014).

The results of this study are in agreement with those reported by Hussein (2012) who stated that gamma irradiation resulted in appearance or disappearance of bands that can be considered as molecular markers for radiation process for Ambrosia maritima plant. Jyoti et al. (2009) explained the effect of gamma irradiation on DNA that gamma rays induce ionization of molecules to create free radicals that attack the DNA molecule which causes breaks in one or the two strands of DNA during sterilization.

\section{Conclusion}

Gamma radiation can be used as a mutagenic agent for forming and producing new compounds in the medicinal plants Moringa. The SCoT technique can be applied to confirm the effect of gamma rays treatments and obtain markers associated with new compound production.

Acknowledgment: We gratefully acknowledge the assistance of Dr. Lammya Mostafa, Assistant Prof. of Genetics, Genetics Department, Faculty of Agriculture, Ain Shams University for her help and support to achieve the molecular marker work.

\section{References}

AL-Qurainy, F., Khan, S., Nadeem, M. and Tarroum, M. (2015) SCoT marker for the assessment of genetic diversity in Saudi Arabia date palm cultivars. Pak. J. Bot. 47(2), 637-643.

Bahraminejad, A. and Nejad, G.M. (2015) Genetic diversity analysis of date palm (Phoenix dactylifera L.) genotypes using RAPD markers. Annual Rese. Rev. Biol. 5(1), 41-47.

Bhattacharya, A., Ghosh, G., Agrawal, D., Sahu, P.K., Kumar, S. and Mishra, S.S. (2014) GC-MS profiling of ethanolic extract of Moringa oleifera leaf. Inter. J. Pharm. Biol. Sci. 5(4), 263-275.

Chen, H., He, X.H., Luo, C., Zhu, J.H. and Li, F. (2010) Analysis on the genetic diversity of 24 longan (Dimocarpus longan) accessions by SCoT markers. Acta Hort. Sin. 37(10), 1651-1654.

Collard, B.C.Y. and Mackill, D.J. (2009) Start codon targeted (SCoT) polymorphism: A simple, novel DNA marker technique for generating genetargeted markers in plants. Plant Mol. Biol. Rep. 27, 86-93.

Esnault, M.A, Legue, F. and Chenal, C. (2010) Ionizing radiation: Advances in plant response. Environ. Expt. Bot. 68(3), 231-237.

Fahey, J.W. (2005) Moringa oleifera: A review of the 
medical evidence for its nutritional, therapeutic, and prophylactic properties. Part 1. Trees Life J. 1, 1-15.

Fanaro, G.B., Duarte, R.C., Santillo, A.G., Pinto e' Silva, M.E.M., Purgatto, E. and Villavicencio, A.L.C.H. (2012) Evaluation of $\gamma$-radiation on oolong tea odor volatiles. Rad. Phys. Chem. 81, 1152-1156.

Gopalakrishnan, S. and Kalaiarasi, T. (2013) Determination of biologically active constituents of the fruits of Cucumis sativus Linn. using GC-MS analysis. Inter. J. Biol. Pharm Res. 4(7), 523-527.

Gorji, A.M., Poczai, P. and Polgar, Z. (2011) Efficiency of arbitrarily amplified dominant markers (SCOT, ISSRs and RAPD) for diagnostic finger printing in tetraploidpotato. Am. J. Pot. Res. 88, 226-237.

Graham, C.S. and Henry, C. (1997) Inheritance of fertility restoration of cytoplasmic male sterility in Indica rice. Rice Genetics. Proceedings of the Int. Rice Genetics Symposium, 27-31, pp. 649-654.

Han, G.H., Su, Q., Wang, W.S., Jia, Z.G., Hong, Q.B. and Liang, G. (2011) Establishment and application of SCoT molecular marker system for Citrus. Acta Hort. Sin. 38(7), 1243-1250.

Hussein, O.S. (2012) Protein electrophoresis and DNA in herbs produced from irradiated Ambrosia maritima seeds grown under soil salinity and their resistance to insect. Am. J. Plant Physiol. 7(6), 261-268.

Jyoti, P.M., Sukalyan, C.S.K., Subrata, P., Jiin-Shuh, J., Alok, C., Anindita, C. and Subhas, C.S. (2009) Effects of gamma irradiation on edible seed protein, amino acids and genomic DNA during sterilization. Food Chem. 114, 1237-1244.

Karthika, S., Ravishankar, M., Mariajancyrani, J. and Chandramohan, G. (2013) Study on phytoconstituents from Moringa oleifera leaves. Asian J. Plant Sci. Res. 3(4), 63-69.

Leone, A., Spada, A., Battezzati, A., Schiraldi, A., Aristiland, J. and Bertoli, S. (2015) Cultivation, genetic, ethnopharmacology, phytochemistry and pharmacology of Moringa oleifera leaves: An Overview. Int. J. Mol. Sci. 16, 12791-12835.

Li, M.M., Wu, L.Y., Zhao, T., Xiong, L., Huang, X., Liu, Z.H., Fan, X.L., Xiao, C.R., Gao, Y., Ma, Y.B., Chen, J.J., Zhu L.L. and Fan, M. (2011) The protective role of 5-HMF against hypoxic injury. Cell Stress Chaperones, 16, 267-273.

Li, W., Qu, X., Han, Y., Zheng, S., Wang, J. and Wang, Y. (2015) Ameliorative effects of 5-hydroxymethyl2-furfural (5-HMF) from Schisandra chinensis on alcoholic liver oxidative injury in mice. Int. J. Mol. Sci. 16, 2446-2457.

Mahmood, K., Mugal, T. and Haq, I.U. (2010) Moringa oleifera: A natural gift- A review. J. Pharm. Sci. Res. 2, 775-781.

Mohamed, S.A. and Khan, J.A. (2013) Antioxidant capacity of chewing stick miswak Salvadora persica. BMC Complement. Alternat. Med. 13(40), $1-6$.

Mukunzi, D., Nsor-Atindana, J., Xiaoming, Z., Gahungu, A., Karangwa, E. and Mukamurezi, G. (2011) Comparison of volatile profile of Moringa oleifera leaves from Rwanda and China using HSSPME. Pak. J. Nutr. 10(7), 602-608.

Racchi, M.L., Bove, A., Turchi, A., Bashir, G., Battaglia, M. and Camussi, A. (2014) Genetic characterization of Libyan date palm resources by microsatellite markers. Biotech. 4, 21-32.

Sankhla, A.K., Malik, C.P. and Parashar, M. (2015) A review on start codon targeted (SCoT) marker. $J$. Plant Sci. Res. 31(2), 153-160.

Seo, H.Y., Kim, J.H., Song, H.P., Kim, D.H., Byun, M.W., Kwon, J.H. and Kim, K.S. (2007) Effects of gamma irradiation on the yields of volatile extracts of Angelica gigas Nakai. Rad. Phys. Chem. 76, 1869-1874.

Shahlaei, A., Torabi, S. and Khosroshahli, M. (2014) Efficiacy of SCoT and ISSR marekers in assesment of tomato (Lycopersicum esculentum Mill.) genetic diversity. Int. J. Biosci. 5(2), 14-22.

Shim, S.L., Hwang, I.M., Ryu, K.Y., Jung, M.S., Seo, H.Y., Kim, H.Y., Song, H.P., Kim, J.H., Lee, J.W., Byun, M.W., Kwon, J.H. and Kim, K.S. (2009) Effects of $\gamma$ - irradiation on the volatile compounds of medicinal herbs, Paeoniae radix. Rad. Phys. Chem. 78, 665-669.

Silva, T.M., Miranda, R.R.S., Ferraz, V.P., Pereira, M.T., de Seiqueira, E.P. and Alcantara, A.F.C. (2013) Changes in the essential oil composition of 
leaves of Echinodorus macrophyllus exposed to $\gamma$ radiation. Brazil. J. Pharmacognosy, 23(4), 600-607.

Sundaram, S., Verma, S.K. and Dwivedi, P. (2011) In vitro cytotoxic activity of Indian medicinal plants used traditionally to treat cancer. Asian J. Pharm. Clinic. Res. 4(1), 27-29.

Thilza, I., Sanni, S., Zakari, A., Muhammed, T. and Musa, B. (2010) In vitro antimicrobial activity of water extract of Moringa oleifera leaf stalk on bacteria normally implicated in eye disease. Academia Arena, 2, 80-83.

Vandenhove, H., Vanhoudt, N., Cuypers, A., Van, H.M., Wannijn, J. and Horemans, N. (2010) Lifecycle chronic gamma exposure of Arabidopsis thaliana induces growth effects but no discernible effects on oxidative stress pathways. Plant Physiol. Biochem. 48, 778-786.
Xu, Q., Li, Y.H. and Lv, X.Y. (2007) Investigation on influencing factors of 5-HMF content in Schisandra. J. Zhejiang Univ. Sci. B. 8, 439-445.

Zhang, J., Xie, W., Wang, Y. and Zhao, X. (2015) Potential of start codon targeted (SCoT) markers to estimate genetic diversity and relationships among Chinese Elymus sibiricus accessions. Molecules, 20, 5987-6001.

Zhao, L., Chen, J., Su, J., Li, L., Hu, S., Li, B., Zhang, X., Xu, Z. and Chen, T. (2013) In vitro antioxidant and antiproliferative activities of 5-hydroxymethylfurfural. J. Agric. Food Chem. 61 (44), 10604-10611.

(Received 11/12/2017; accepted $12 / 3 / 2018$

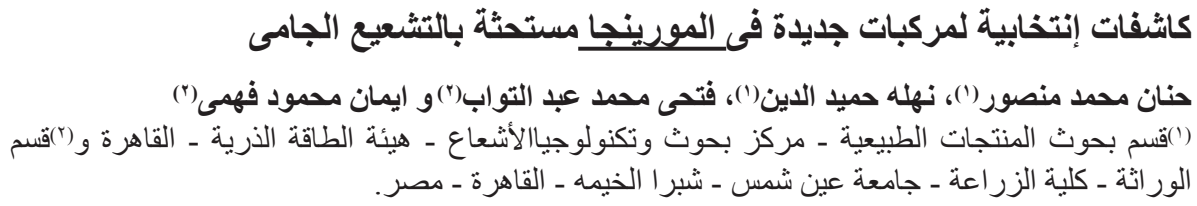

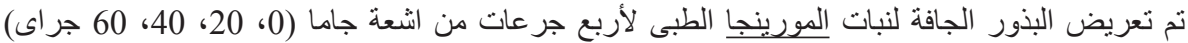

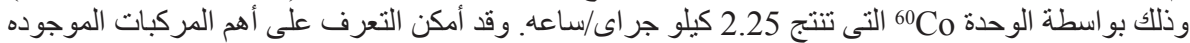

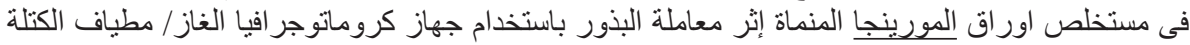

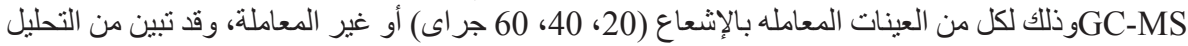

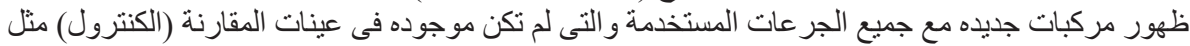

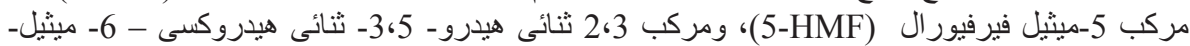

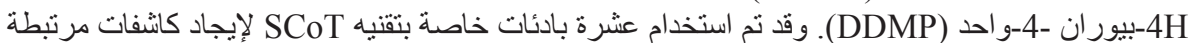

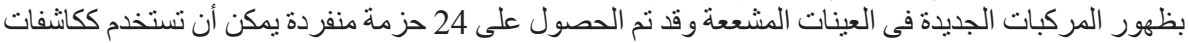

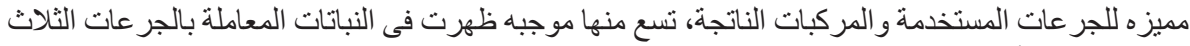

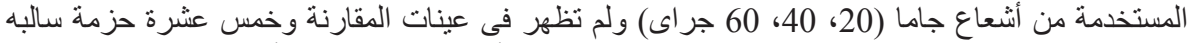

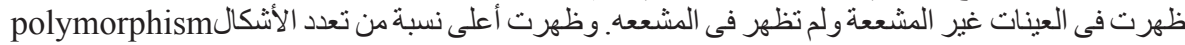

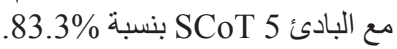

